\title{
RESEARCH
}

Open Access

\section{The TGF $\beta$-miR-499a-SHKBP1 pathway induces resistance to EGFR inhibitors in osteosarcoma cancer stem cell-like cells}

\author{
Tian Wang ${ }^{\dagger}$, Dexing Wang ${ }^{\dagger}$, Lian Zhang, Ping Yang, Jing Wang, Qi Liu, Fei Yan and Feng Lin * (D)
}

\begin{abstract}
Background/aims: A novel paradigm in tumor biology suggests that osteosarcoma (OS) chemo-resistance is driven by osteosarcoma stem cell-like cells (OSCs). As the sensitivity of only a few tumors to epidermal growth factor receptor (EGFR) tyrosine kinase inhibitors (TKIs) can be explained by the presence of EGFR tyrosine kinase (TK) domain mutations, there is a need to elucidate mechanisms of resistance to EGFR-targeted therapies in OS that do not harbor TK sensitizing mutations to develop new strategies to circumvent resistance to EGFR inhibitors.

Methods: As a measure of the characters of OSCs, serum-free cultivation, cell viability test with erlotinib, and serial transplantation in vivo was used. Western blot assays were used to detect the association between erlotinib resistance and transforming growth factor beta (TGFB)-induced epithelial-to-mesenchymal transition (EMT) progression. By using TaqMan qPCR miRNA array, online prediction software, luciferase reporter assays and western blot analysis, we further elucidated the mechanisms.
\end{abstract}

Results: Here, CD166 cells are found in 10 out of 10 tumor samples. We characterize that CD166 ${ }^{+}$cells from primary OS tissues bear hallmarks of OSCs and erlotinib-resistance. TGFß-induced EMT-associated kinase switch is demonstrated to promote erlotinib-resistance of $\mathrm{CD}_{166^{+}} \mathrm{OSC}$. Further mechanisms study show that TGF $\beta$-induced EMT decreases miR499a expression through the direct binding of Snail1/Zeb1 to miR-499a promoter. Overexpression of miR-499a in CD166 ${ }^{+}$ OSCs inhibits TGF $\beta$-induced erlotinib-resistance in vitro and in vivo. SHKBP1, the direct target of miR-499a, regulates EGFR activity reduction occurring concomitantly with a TGF $\beta$-induced EMT-associated kinase switch to an AKT-activated EGFRindependent state. TGF $\beta$-induced activation of AKT co-opts an increased SHKBP1 expression, which further regulates EGFR activity. In clinic, the ratio of the expression levels of SHKBP1 and miR-499a is highly correlated with EMT and resistance to erlotinib.

Conclusion: TGF $\beta-$ miR-499a-SHKBP1 network orchestrates the EMT-associated kinase switch that induces resistance to EGFR inhibitors in $\mathrm{CD}_{166^{+}}$OSCs, implies that inhibition of TGF $\beta$ induced EMT-associated kinase switch may reverse the chemo-resistance of OSCs to EGFR inhibitors. We also suggest that an elevated SHKBP1/miR-499a ratio is a molecular signature that characterizes the erlotinib-resistant OS, which may have clinical value as a predictive biomarker.

Keywords: TGFß, Epithelial-to-mesenchymal transition, miR-499a, SHKBP1, EGFR, Osteosarcoma stem cell-like cells

\footnotetext{
*Correspondence: linfengdoc@163.com

${ }^{\dagger}$ Tian Wang and Dexing Wang contributed equally to this work.

Department of Oncology, The Eighth People's Hospital of Shanghai, No. 8

Caobao Road, Xuhui District, Shanghai 200233, People's Republic of China
}

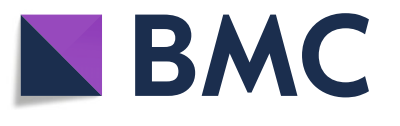

(c) The Author(s). 2019 Open Access This article is distributed under the terms of the Creative Commons Attribution 4.0 International License (http://creativecommons.org/licenses/by/4.0/), which permits unrestricted use, distribution, and reproduction in any medium, provided you give appropriate credit to the original author(s) and the source, provide a link to the Creative Commons license, and indicate if changes were made. The Creative Commons Public Domain Dedication waiver (http://creativecommons.org/publicdomain/zero/1.0/) applies to the data made available in this article, unless otherwise stated. 


\section{Background}

Osteosarcoma (OS) is the third most common cancer in adolescence and is the most frequent form of primary bone tumors [1]. The drug resistance induced recurrence and metastasis remarkably contribute to the failure in OS therapy [2, 3]. A rising number of observations indicates that cancer stem cells (CSCs), characterized by increased tumorigenicity, self-renewal ability and multipotency, have been described contributing to tumor progression and resistance to chemo-therapy $[4,5]$. In OS, existence of osteosarcoma stem cell-like cells (OSCs) may explain the high rate of tumor relapse after standard therapies. Zhang W. et, al. [6] showed that OSCs results in a critical advantage when establishing lung macro-metastases. Crasto et al. [7] used disulfiram as an ALDH inhibitor to target the CSC subpopulation in a murine osteosarcoma model. They found that a reduction in metastatic tumor burden after treatment, which was comparable to that achieved with doxorubicin chemotherapy. Therefore, therapeutics targeting OSCs may be an effective strategy to overcome chemo-resistance and preventing distant metastasis.

As the heterogeneity of osteosarcoma, rather than targeting OS cells themselves, targeting the key actors secreted in the microenvironment, such as transforming growth factor beta (TGF $\beta$ ), supplies an alternative approach to overcome OSCs. Studies have shown that overexpression of TGF $\beta$ is a hallmark of many cancers, including OS $[8,9]$. In OS, increase TGF $\beta$ level is associated with high-grade and metastases [9]. Furthermore, studies demonstrated that TGF $\beta$ triggered epithelialto-mesenchymal transition (EMT), tumor-initiating cell stemness, metastasis and invasion [10-13]. However, few studies uncovering the molecular mechanism underlying TGF $\beta$-induced EMT to affect the chemo-resistance of OSCs.

The resistance or sensitivity of some tumors to epidermal growth factor receptor (EGFR) inhibitors can be explained by the presence of mutations in the EGFR TK domain [14]. However, such mutations are rare in tumors other than non-small cell lung carcinoma (NSCLC) [15, 16]. Thus, there is an urgent need to elucidate the precise molecular mechanisms underlying resistance to EGFR-targeted TKIs to provide treatment selectively to those patients who do not harbor EGFR mutations but will nonetheless respond to TKIs. In OS, EGFR has been found to be overexpressed [17] and in vitro studies have reported the expression of EGFR as well as effective inhibition of OS growth by EGFR inhibitors [18, 19], but few activating mutations in the EGFR TK domain in OS cells $[16,19]$. At the meantime, epithelial tumor cells are more sensitive to EGFR inhibitors than tumor cells that acquired mesenchymal characteristics [20]. In multiple types of tumors, like OS, the response to EGFR-targeted agents is inversely correlated with EMT [21]. It suggests that OSCs and EMT are the common denominator resistant to EGFR inhibitors. Nevertheless, the precise molecular link between EMT and EGFR inhibitors in OSCs remain unknown.

Here, $\mathrm{CD} 166^{+}$cells are found in 10 out of 10 tumor samples. We characterize that $\mathrm{CD} 166^{+}$cells from primary OS tissues bear hallmarks of OSCs and erlotinib-resistance. TGF $\beta$-induced EMT-associated kinase switch is demonstrated to promote erlotinib-resistance of CD166 ${ }^{+}$OSCs. Further mechanisms study show that TGF $\beta$-induced EMT decreases miR-499a expression through the direct binding of Snail1/Zeb1 to miR-499a promoter. Overexpression of miR-499a in CD166 ${ }^{+}$OSCs inhibits TGF $\beta$-induced erlotinib-resistance in vitro and in vivo. SHKBP1, the direct target of miR-499a, regulates EGFR activity reduction occurring concomitantly with a TGF $\beta$-induced EMT-associated kinase switch to an AKT-activated EGFR-independent state. TGF $\beta$-induced activation of AKT co-opts an increased SHKBP1 expression, which further regulates EGFR activity. In clinic, the ratio of the expression levels of SHKBP1 and miR-499a is highly correlated with EMT and resistance to erlotinib.

\section{Materials and methods \\ Sample collection}

Ten primary osteosarcoma tissue samples were obtained from a consecutive series of consenting patients according to the approval of The Eighth People's Hospital of Shanghai from January 2013 to June 2018. All patients were diagnosed with primary osteosarcoma and did not show other tumor occurrences.

\section{Mutation analysis of the EGFR TK domain}

Genomic DNA was extracted from $\mathrm{CD}_{166^{+}}$cells from 10 fresh osteosarcoma tumors by a High Pure PCR template Preparation kit (Roche, Mannheim, Germany). PCR and real-time amplification monitoring of peptide nucleic acid PCR clamping were performed using a CFX 96 system (Bio-Rad). Genomic DNA was used to amplify EGFR exons 18, 19, 20, and 21 using primer sequences: Ex18-F, 5' -AGGTGACCCTTGTCTCTGTG-3' and Ex18-R, 5' -CCTGTGCCAGGGACCTTAC-3' for exon 18; Ex19-F, 5'-CATGTGGCACCATCTCACAA-3'and Ex19-R, 5'-CCCACACAGCAAAGCAGAA-3' for exon 19; Ex20-F, 5' -ATCGCATTCATGCGTCTTC-3' and Ex20-R, 5' -GTCTTTGTGTTCCCGGACAT-3' for exon 20; Ex21-F, 5' -CCTCACAGCAGGGTCTTCTC-3' and Ex21-R, 5' -GGAAAATGCTGGCTGACCTA-3' for exon 21. PCR products were purified using the Qiaex II gel extraction kit (Qiagen, Valencia, Calif) or Microcon-100 purification columns (Millipore, Billerica, Mass). Purified DNA was then sequenced in both the sense and antisense directions on all cases by Big Dye Terminator (v.3) Chemistry using PCR primers on Applied Biosystem 3700 DNA Analyzers. 


\section{Sphere formation and propagation}

Solid osteosarcoma tissues were finely minced and washed in DMEM/F12 (Gibico Invitrogen, USA). Then they were incubated with Accumax 1X (Innovative Cell Technologies, USA) for $30 \mathrm{~min}$ at $37^{\circ} \mathrm{C}$. Single-cell suspension was obtained by filtering digested tissue. Single-cells were plated at a density of $10^{4}$ cells in serum-free medium DMEM/F12 (Gibico Invitrogen, USA), supplemented with commercial hormone mix B27 (Gibico Invitrogen, USA), EGF (10 ng/mL; PeproTech), bFGF (10 ng/mL; PeproTech), and heparin $(2 \mu \mathrm{g} / \mathrm{mL})$. The medium of all the spheres was replaced with fresh growth factors twice a week until cells started to grow forming floating aggregates. Cultures were expanded by enzymatic digestion of spheres with Accumax 1X (Innovative Cell Technologies, USA), followed by re-plating of both single cells in complete fresh medium. All cells were cultured at $37^{\circ} \mathrm{C}$ in a $5 \% \mathrm{CO}_{2}$ humidified incubator.

\section{Flow cytometry and fluorescence-activated cell sorting (FASC)}

Tumor spheres were expanded by enzymatic digestion of spheres with Accumax 1X (Innovative Cell Technologies, USA). Single-cells were incubated in staining solution containing 1\% BSA with the specific antibodies at appropriate dilutions. Cells were stained with primary conjugated CD166-FITC (BD Biosciences, USA) antibodies, or corresponding isotype-matched controls. Fluorescence-activated cell sorting (FASC) was performed on cells stained with CD166-FITC (BD Biosciences, USA). Quality of sorting was monitored by flow cytometry with specific antibody for CD166-FITC.

\section{MTT assay}

The MTT assay (Sigma Aldrich, USA) was used to determine relative cell growth every $24 \mathrm{~h}$ for cell growth curves. A total of $10^{5}$ cells $/ \mathrm{ml}$ were plated into 96-well plates, incubated at $37^{\circ} \mathrm{C}$, and cultured overnight. $20 \mu \mathrm{l}$ of $5 \mathrm{mg} / \mathrm{ml}$ MTT was added to the media for $4 \mathrm{~h}$ incubation at $37^{\circ} \mathrm{C}$. Following removal of the culture medium, the remaining crystals were dissolved in $150 \mu \mathrm{l}$ DMSO (Sigma Aldrich, USA). Absorbance (A) was measured spectrophotometrically in a microplate reader (Bio-Rad, USA) at a wavelength of $490 \mathrm{~nm}$. The curve of growth was drawn with the absorbance (A) measured spectrophotometrically in a microplate reader (Bio-Rad, USA) at a wavelength of $490 \mathrm{~nm}$.

\section{Measurement of TGF $\beta$ in tumor cell supernatants}

A total of $1 \times 10^{6}$ cells were plated in media containing $0.1 \%$ FBS. Tumor cell supernatants were evaluated by ELISA (R\&D Systems) to determine the amount of TGF- $\beta$ expressed by 1 X $10^{6}$ cells per $24 \mathrm{~h}$.

\section{Western-blotting}

Protein extracts were resolved through 8 to $12 \%$ SDS-PAGE; transferred to nitrocellulose membranes; and probed with monoclonal antibody against EGFR, HER2, AKT, FGFR, Vimentin, E-Cadherin, GAPDH, etc. The membranes were washed and incubated with a horseradish peroxidase (HRP)-conjugated secondary antibody. The different treated cells were washed with ice-cold PBS and then lysed by protein lysate (Pierce, USA). After centrifugation at $12,000 \mathrm{rpm}$ for $10 \mathrm{~min}$ at $4{ }^{\circ} \mathrm{C}$, the protein concentration was measured by $\mathrm{BCA}$ protein assay kit (Pierce, USA). Then, all proteins were resolved on a $10 \%$ SDS denatured polyacrylamide gel and were then transferred onto a PVDF membrane (Millipore, USA). The membranes were washed and incubated with a horseradish peroxidase (HRP)-conjugated secondary antibody. Protein expression was detected and quantified using the ODYSSEY Infrared Imaging System (Li-COR Biosciences, USA).

\section{Quantitative real-time RT-PCR (qPCR)}

Total RNA for qPCR analysis was extracted using Trizol (Invitrogen, USA), treated with DNase I (Takara, USA) to eliminate contaminating genomic DNA, and reversetranscribed into cDNA with the Reverse Transcriptase MMLV (Takara, USA). Real time PCR was performed using a SYBR Green Reagents (Bio-Rad, USA) on the iQ5 Real-Time PCR Detection System (Bio-Rad, USA). Expression of genes with relative to $\beta$-actin was determined using the $2^{-\Delta \Delta \mathrm{Ct}}$ method.

\section{Lentiviral infection}

$\mathrm{CD}_{166}{ }^{+}$cells were spin-infected with $1 \mathrm{ml}$ of NC-si-RNA (Gene Copoeia, USA), SHKBP1-si-RNA lentiviral knockdowns packbag or miR-499a mimics (Gene Copoeia, USA) packbag. $\mathrm{CD} 166^{-}$cells were spin-infected with $1 \mathrm{ml}$ of pcDNA3.1-NC, pcDNA3.1-Snail1 and pcDNA3.1-Zeb1 (Gene Copoeia, USA) packbag. For all systems, cells were infected with lentiviral media at a multiplicity of infection of 20, in the presence of $8 \mu \mathrm{g} / \mathrm{mL}$ polybrene (Sigma-Aldrich, USA) overnight in a $37^{\circ} \mathrm{C}$ incubator. Stable clones were selected using puromycin. The expression of was tested by qPCR.

\section{Chromatin immunoprecipitation (ChIP) and promoter assays}

ChIP assays were performed in $\mathrm{CD}_{166^{-}}-\mathrm{hSnail}-\mathrm{HA}$ and $\mathrm{CD}_{166^{-}}^{-}$hZeb1 cells. For detection of interaction between the EMT factors and the endogenous miR-499a promoters, anti-hSnail-HA (Roche Diagnostics) or anti-Zeb1 (Santa Cruz) anti-bodies or unspecific rat IgG (Jackson ImmunoResearch Laboratories) were used. Around $100 \mathrm{bp}$ fragments of the miR-499a promoter sequences were amplified using the primer: F, 5' GTTG 


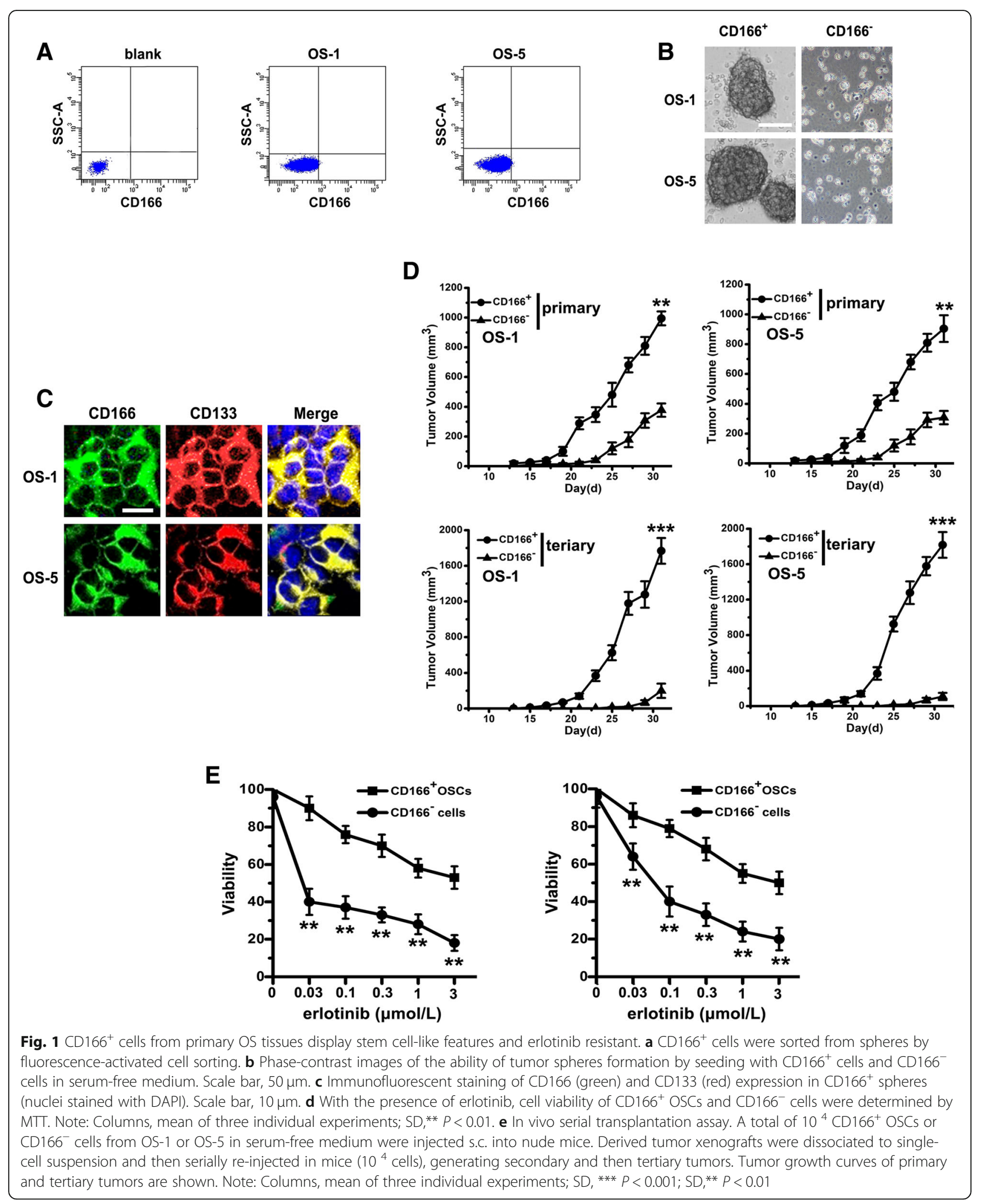


GGTTTCAGGGCTTTG $3^{\prime}, \quad \mathrm{R}, \quad 5^{\prime}$ AgAGCAGCACCCTCCAGG $3^{\prime}$. As for the promoter assays, for analyses of the miR-499a promoters, pGL3 reporter plasmids containing the miR-499a (2321 to $1120 \mathrm{bp}$ ) regulatory sequences fused to luciferase cDNA were used. Co-transfection with b-galactosidase reporter and detection of relative luciferase units.

\section{In vivo studies of Tumorigenicity}

All experiments were carried out with female NOD/ SCID mice, 3-4 weeks old (HFK Bioscience, China). Mice were maintained at the Animal Core Facility at The Eighth People's Hospital of Shanghai under specific pathogen-free (SPF) condition. All studies on mice were conducted in accordance with the National Institutes of Health 'Guide for the Care and Use of Laboratory Animals'. For establishment of subcutaneously xenograft models were obtained using either $10^{4} \mathrm{CD} 166^{+}$cells or $10^{4} \mathrm{CD}^{-166^{-}}$cells. Cell fragments were implanted NOD/ SCID mice by trocar gauge in both flanks of nude mice (3 mice for each group). The tumor volume was calculated by the formula $\mathrm{V}\left(\mathrm{mm}^{3}\right)=0.52 \times$ length $(\mathrm{mm}) \times$ width $^{2}\left(\mathrm{~mm}^{2}\right)$. About 4-5 weeks after injection, the animals were sacrificed and flank tumours were removed.

\section{Statistical analysis}

SPSS13.0 software was used. Each experiment was performed at least three times. The data were expressed as mean $\pm \mathrm{SD}$, and one-way ANOVA and an unpaired Student's t-test were used to determine the significant differences of all the results. Significances are ${ }^{* * *}, p<$ $0.001 ; * * * 0<0.01 ; *, p<0.05$.

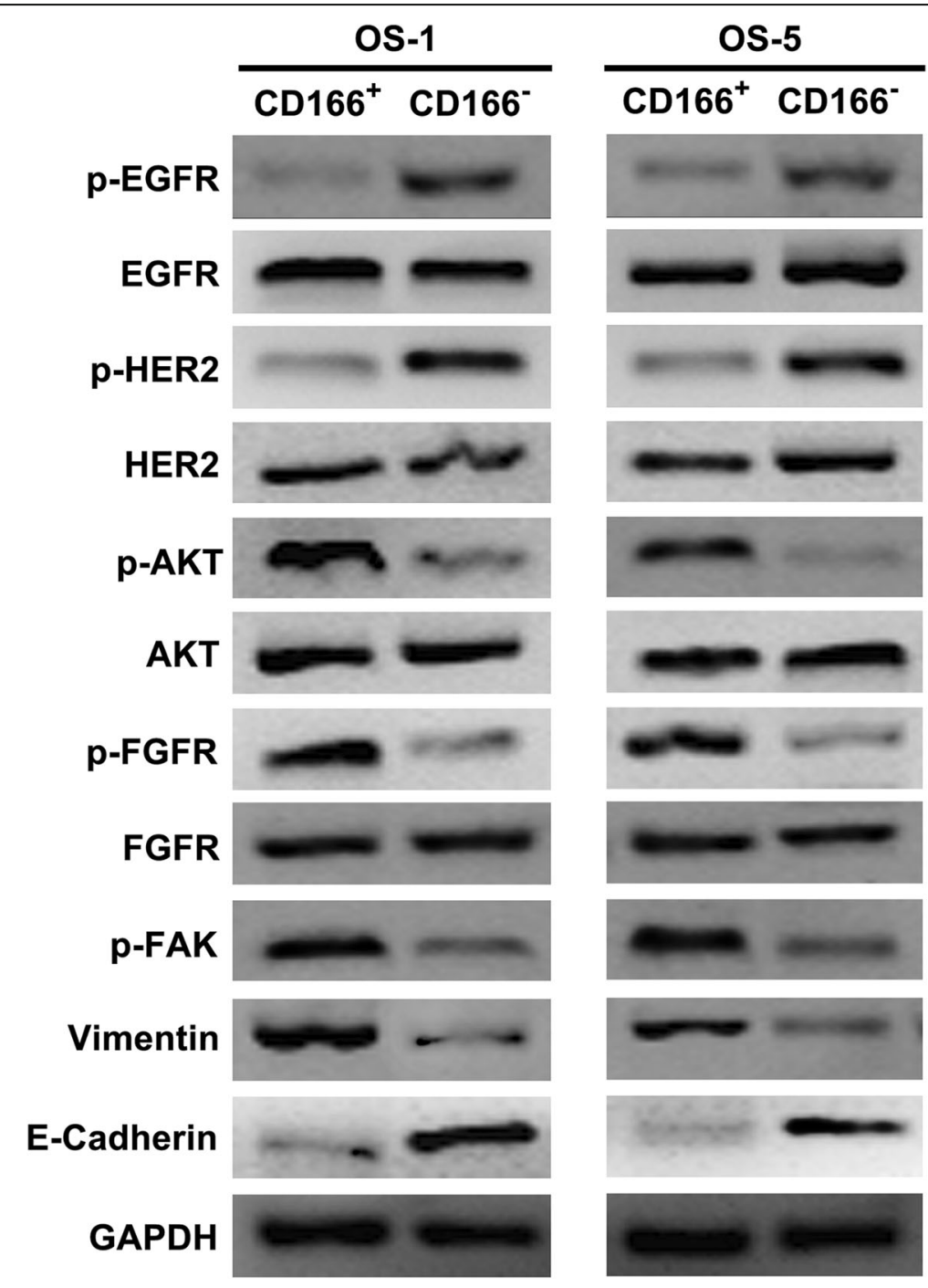

Fig. 2 CD $166^{+}$OSCs is associated with a kinase switch that enables EGFR-independent activation of AKT. Western-blotting was used with antibodies specific for phosphorylated and total EGFR, HER2, AKT, FGFR, and p-FAK, Vimentin, E-Cadherin. GAPDH was used as the control 

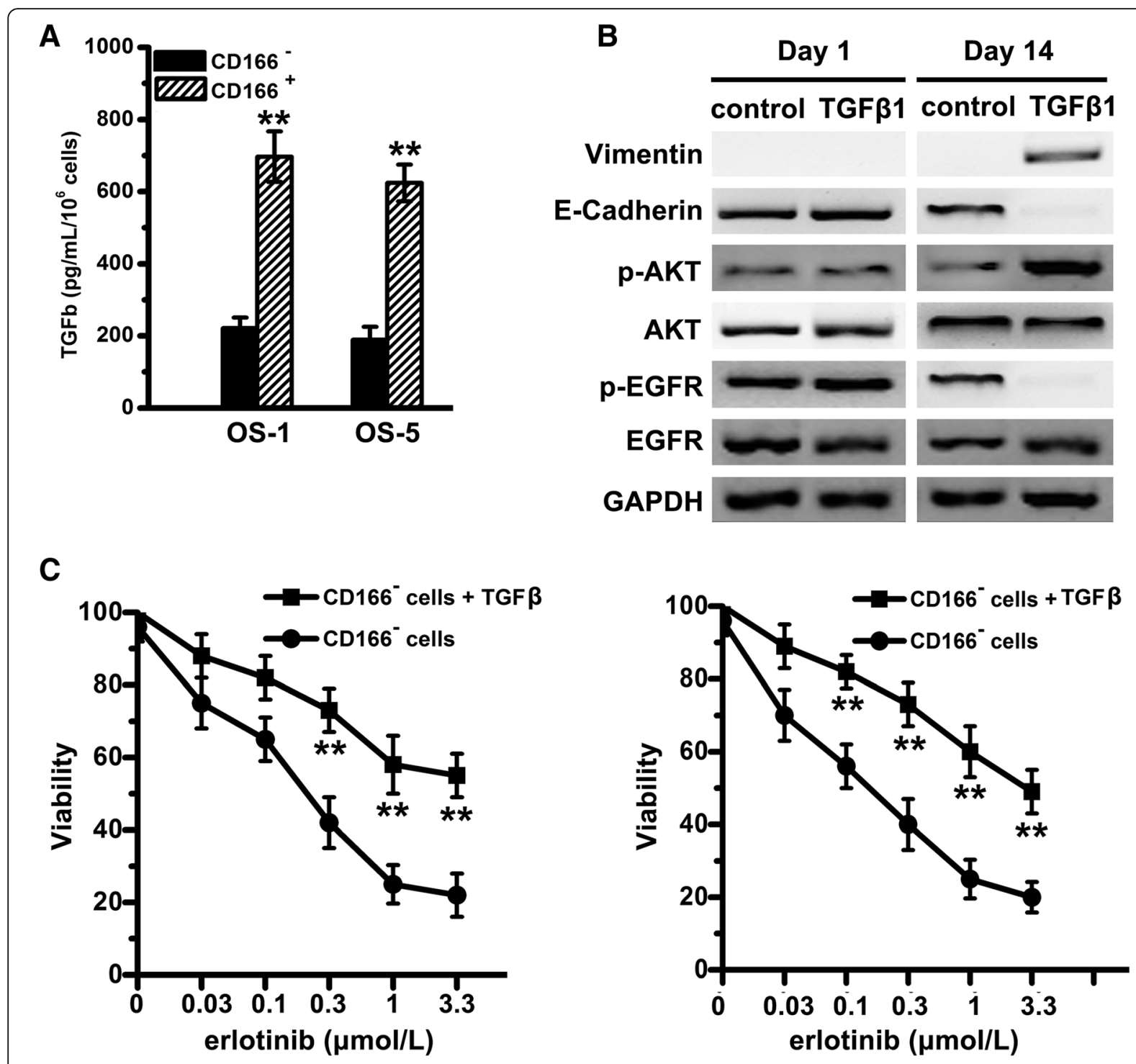

D

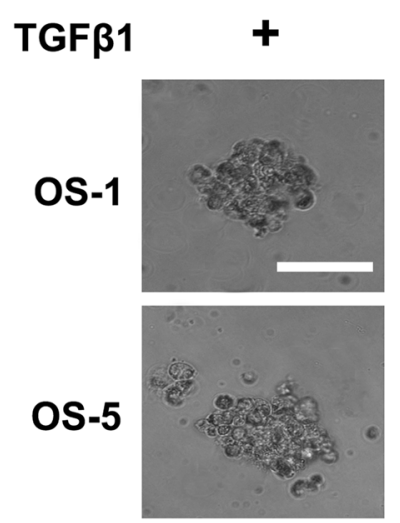

E
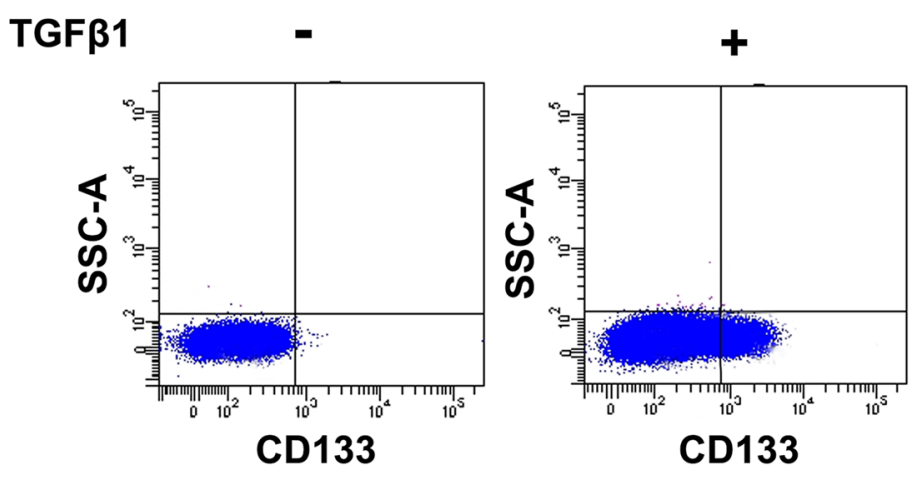
(See figure on previous page.)

Fig. 3 TGF $\beta$ induces an EMT-associated kinase switch that promotes erlotinib resistance of CD166 ${ }^{+}$OSCs. a Tumor cell supernatants of CD166 ${ }^{+}$ and $\mathrm{CD}_{166^{-}}$cells from OS-1 or OS-5 were collected and differential levels of TGF $\beta$ production were analyzed by ELISA. Note: Columns, mean of three individual experiments; $\mathrm{SD}_{1}^{* *} P<0.01$. b Immunoblot analysis was performed with antibodies against phosphorylated and total AKT, EGFR and Vimentin, E-Cadherin. GAPDH was used as the control. $\mathbf{c}$ With the presence of erlotinib, cell viability of CD166 cells with or without the treatment of TGF $\beta 1$ were determined by MTT. Note: Columns, mean of three individual experiments; $S D$, ${ }^{* *} P<0.01$. $\mathbf{d}$ Phase-contrast images of the ability of tumor spheres formation by seeding with CD166 cells with or without the treatment of TGF $\beta 1$ in serum-free medium. Scale bar, $50 \mu \mathrm{m}$. e Flow cytometry analysis of CD133 in CD166- cells (from OS-1) without the treatment of TGF $\beta 1$

\section{Results}

$\mathrm{CD}_{166^{+}}$cells from primary OS tissues display stem celllike features and erlotinib resistant

We analyzed 10 primary tissue samples derived from a consecutive series of OS patients. By using the surface marker CD166 alone, flow cytometry analysis showed the presence of a variable fraction of $\mathrm{CD} 166^{+}$cell populations in 10 out of 10 tumor samples, varying from $0.01 \%$ to a maximum of $0.47 \%$ (Fig. 1a, Additional file 1 Table S1). CSCs are believed to be able to form spheres in serum-free cultivation. Thus, we sorted both $\mathrm{CD}_{166^{+}}$and CD166 ${ }^{-}$cells from OS-1 and OS- 5 by FACS. CD $166^{+}$cells were able to form compact self-renewing spheres in serum-free medium. These tumor spheres were at least passaged 10 times, indicating the self-renewable ability of these tumor spheres (data were not shown). On the other hand, CD166 ${ }^{-}$cells could not form compact spheres (Fig. 1b). By staining with CD133 in CD166 ${ }^{+}$cells, we noted that almost all of $\mathrm{CD} 166^{+}$cells expressed CD133 that was putative marker for CSCs (Fig. 1c).

Next, we compared the tumorigenic ability in $\mathrm{CD}_{166^{+}}$ cells with $\mathrm{CD}_{166^{-}}$cells and found that both $\mathrm{CD} 166^{+}$and CD166 $6^{-}$cells could form xenografts. However, tumor formation of $\mathrm{CD} 166^{+}$cells was faster and resulted in increased tumor take compared with that observed after injection of CD166 ${ }^{-}$cells (Fig. 1d). By performing serial transplantation assays in nude mice of cells isolated from OS-1 and OS-5 tumor xenografts originally derived from $\mathrm{CD} 166^{+}$or CD166 ${ }^{-}$cells injection. Cells derived from $\mathrm{CD}_{166^{+}}$xenografts were able to generate tumors maintaining the original morphology and proportion of $\mathrm{CD} 166^{+}$cells in primary, secondary, and tertiary transplantation, whereas cells from CD166 $6^{-}$tumors lost tumorigenic potential during serial transplantations (Fig. 1d).

Certain mutations in the EGFR TK domain is one of the factors leading to the resistance to certain TKIs [14]. To determine whether such mutations are present in $\mathrm{CD}_{166^{+}}$cells, the TK domain from exons 18 to 21 was sequenced. However, we did not identify known mutations that have been associated with constitutive EGFR activation in $\mathrm{CD}_{166^{+}}$cells from these 10 primary OS tissue samples. Furthermore, by evaluating the TKIs-resistance of $\mathrm{CD}_{166^{+}}$cells, we showed that with the presence of increasing concentrations of erlotinib from 0 to $3 \mu \mathrm{M}$, cell viability was significantly decreased in both $\mathrm{CD} 166^{-}$cells compared with that in $\mathrm{CD}_{166}{ }^{+}$cells at each concentration (Fig. 1e).

\section{CD166 ${ }^{+}$OSCs is associated with a kinase switch that enables EGFR-independent activation of AKT}

To identify the molecular mechanisms underlying the resistance of OSCs to EGFR TKI, CD166 ${ }^{-}$and CD166 ${ }^{+}$ cells from OS-1 and OS-5 were used to evaluate their different response to erlotinib. We found that the levels of phosphorylated EGFR and HER2 were markedly decreased in $\mathrm{CD} 166^{+}$OSCs, while the expression of p-AKT was significantly increased (Fig. 2). p-FGFR level was also significantly increased (Fig. 2), which suggests that $\mathrm{CD} 166^{+}$OSCs exhibited a switch from EGFR to activation of an alternative tumor cell- specific RTKs (FGFR). To further detect whether resistance to erlotinib in $\mathrm{CD}_{166^{+}}$OSCs is correlated with TGF $\beta$-induced EMT progression, we tested EMT markers and the non-receptor focal adhesion kinase (FAK) expression, which plays the key role in TGF $\beta$-induced EMT progression. The result showed that $\mathrm{CD} 166^{+}$OSCs displayed a mesenchymal phenotype manifested by loss of E-cadherin and acquisition of p-FAK and Vimentin (Fig. 2).

\section{TGF $\beta$ induces an EMT-associated kinase switch that promotes erlotinib resistance of $\mathrm{CD} 166^{+}$OSCs}

To determine whether TGF $\beta$ expression level correlates with erlotinib resistance of $\mathrm{CD} 166^{+}$OSCs, we measured the amount of TGF $\beta$ produced in cell supernatants of both pairs of OS cells. Compared with $\mathrm{CD} 166^{-}$cells, $\mathrm{CD}_{166^{+}} \mathrm{OSCs}$ secreted much higher level TGF $\beta$ (Fig. 3a). We showed that TGF $\beta 1$ treatment resulted in complete EMT by day 14: Vimentin was elevated, while E-cadherin was reduced depending on the time (Fig. 3b). At the meantime, phospho-EGFR was decreased in CD166 ${ }^{-}$cells with TGF $\beta 1$ treatment, nevertheless, AKT activity was significant increase (Fig. 3b), which implies that TGF $\beta$ induces the EMT-associated kinase switch. In line with these molecular alterations, $\mathrm{CD}_{166^{-}}$cells treated with TGF $\beta 1$ acquired a relative resistance to erlotinib (Fig. 3c) and cancer stem cell-like phenotype, including the ability of sphere formation (Fig. 3d) and CD133 expression (Fig. 3e). 
miRNA profiling of $\mathrm{CD} 166^{+}$OSCs

To further detect the underlying mechanisms, we compared miRNAs expression levels in $\mathrm{CD} 166^{+}$OSCs and $\mathrm{CD}_{166^{-}}$cells with or without TGF $\beta 1$ treatment by TaqMan qPCR miRNA array. miRNAs which displayed > 2-fold changes in $\mathrm{CD} 166^{+} \mathrm{OSCs}$ or $\mathrm{CD} 166^{-}$cells with TGF $\beta 1$ were tabulated: In $\mathrm{CD}_{166^{+}}$OSCs from OS-1, 8 upregulated and 10 downregulated miRNAs were found among $\mathrm{CD}_{166^{+}}$OSCs compared with those in $\mathrm{CD} 166^{-}$ cells. In parallel, 8 reproducibly upregulated and 11

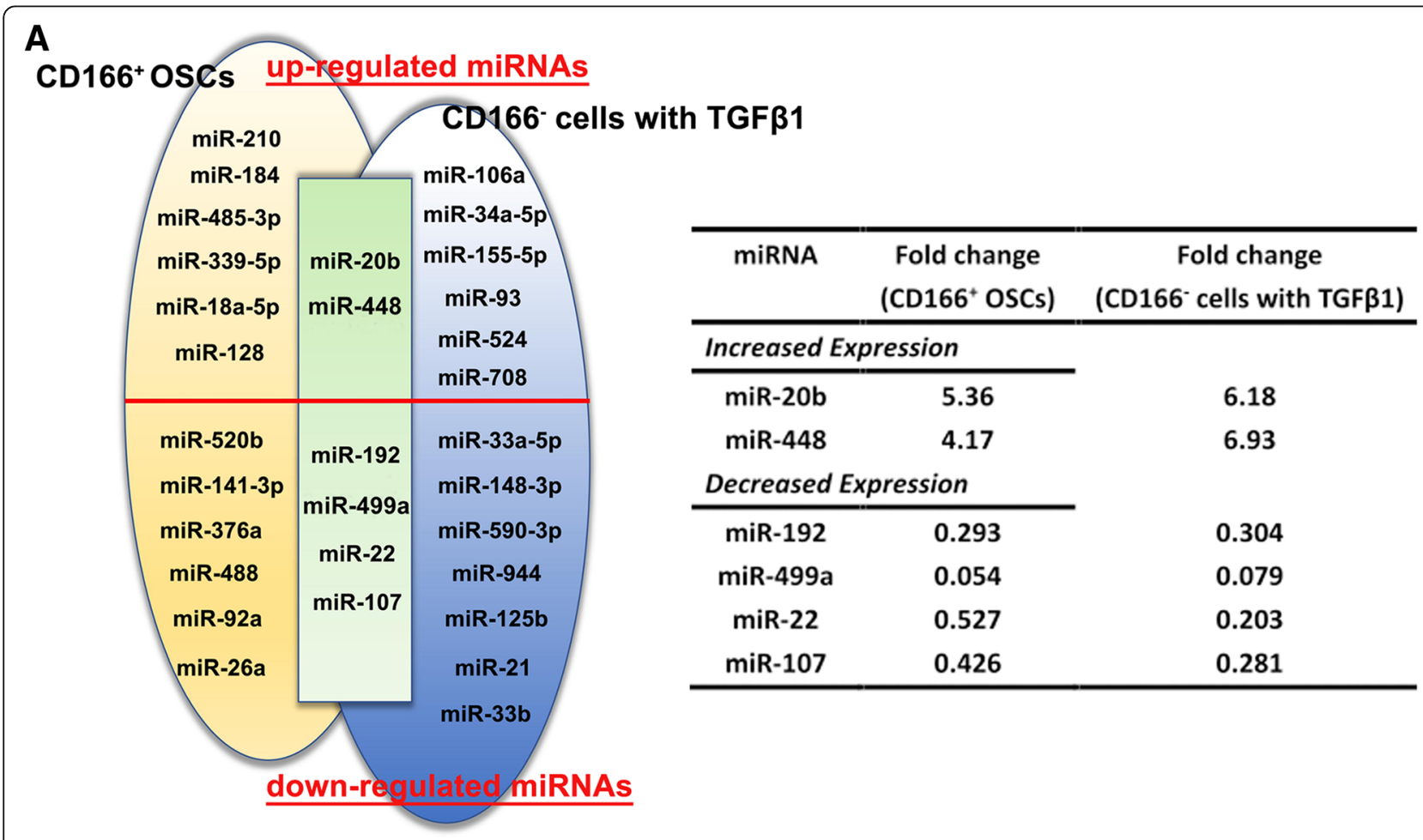

B

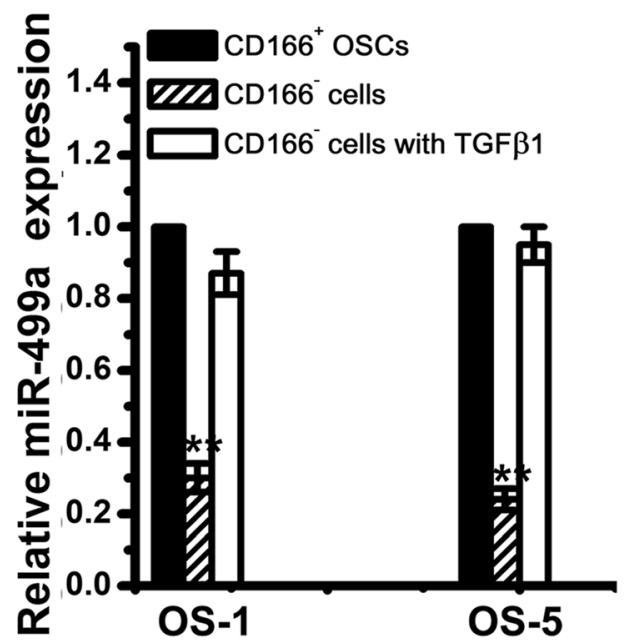

Fig. 4 miRNA profiling of CD166 ${ }^{+}$OSCs. a Venn analyses of the up- and downregulated miRNAs in CD $166^{+}$OSCs from primary OS tissues (left, yellow shaded; $n=3$ ) and in CD166 cells with TGF 1 ( right, blue shaded), compared with CD166- cells, are shown. miRNAs that were significantly and commonly deregulated in both CD166 ${ }^{+}$OSCs and CD166 cells with TGF $\beta 1$ are shown in the overlapping area (green shaded). Only those miRNAs whose expression levels displayed greater than 2-fold decreases or increases were further studied. The table shows a summary of the significantly differentially expressed miRNAs in the overlapping area with fold change. $\mathbf{b}$ Relative expression of miR-499a in CD166 ${ }^{+}$OSCS, CD166 cells with or without TGF $\beta 1$ from OS-1 and OS-5 were examined by qPCR. Note: Columns, mean of three individual experiments; $S D_{1}^{* *}, P<0.01$ 
downregulated miRNAs were identified in $\mathrm{CD} 166^{-}$cells with or without TGF $\beta 1$ treatment. We combined the two different data sets in a Venn diagram: 2 upregulated (miR-20b and miR-448) and 4 downregulated (miR-499a, miR-192, miR-107, miR-22) (Fig. 4a). Among these miRNAs, miR-499a was the most changed (Fig. 4a). Further validation showed that expression of the miR-499a was significantly enhanced upon TGF $\beta 1$ treatment (Fig. 4b).

miR-499a is directly regulated at transcriptional level by Snail1 and Zeb1

To validate the direct role of Snail1 and Zeb1 in miR-499a regulation, ChIP assays were performed. Both Snail1 and Zeb1 bound to the miR-499a promoters
(Additional file 1: Figure S1A). In agreement with these data, miR-499a promoter assays indicated a complete repression in Snail1- or Zeb1- CD166 ${ }^{-}$cells transfectants compared to the control $\mathrm{CD}_{166^{-}}$cells (Additional file 1: Figure S1B).

\section{miR-499a directly targets SHKBP1 expression}

3'UTR of SHKBP1 was indicated as one of putative miR-499a targets by online prediction software, including TargetScan 6.2 and PicTar (Fig. 5a). To further confirm whether SHKBP1 is the direct target of miR-499a, luciferase reporter assays were performed on OSCs transfected with wild type or mutated SHKBP1 3'-UTR. As shown in Fig. 5b, the luciferase activity in OSCs
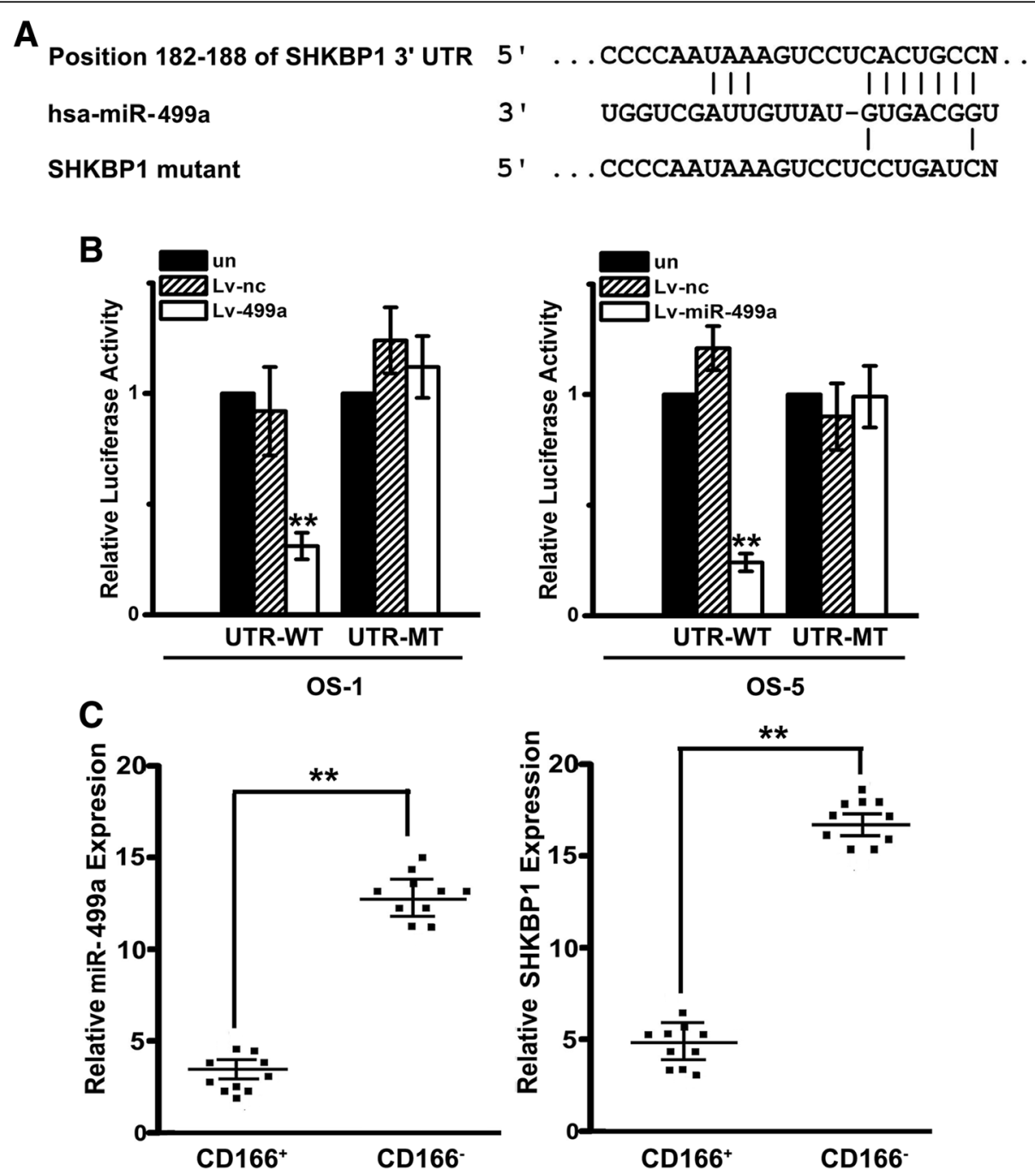

Fig. 5 miR-499a directly targets SHKBP1 expression and SHKBP1 was negatively correlated with miR-499a level in OS tissues. a Illustration of SHKBP1 3'UTR as well as the seed sequence of miR-499a showed the predicted target region on the 3'UTR of SHKBP1 mRNA. b Dual-luciferase reporter assay with co-transfection SHKBP1 3'UTR plasmids and miR-499a mimics. The relative luciferase activity was obtained by firefly luciferase activity normalized against Renilla luciferase activity. Note: Columns, mean of three individual experiments; SD, ${ }^{* *}, P<0.01$. c Down-regulation of miR-499a was observed in OS tissues compared with that in adjacent ones by qPCR (left). Up-regulation of SHKBP1 was observed in OS tissues compared with that in adjacent ones by qPCR (right). Note: Columns, mean of three individual experiments; $\mathrm{SD},{ }^{* *}, P<0.01$ 


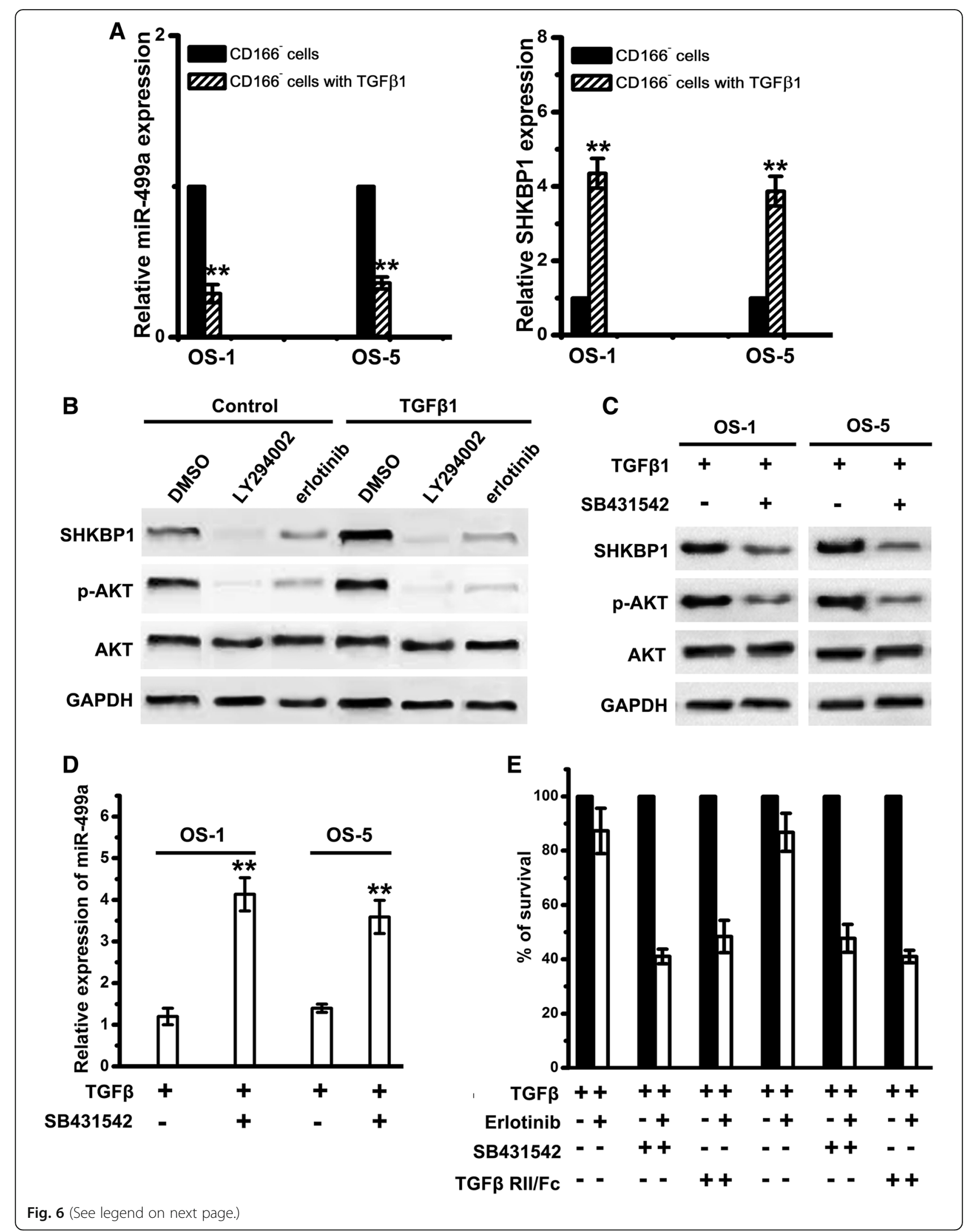




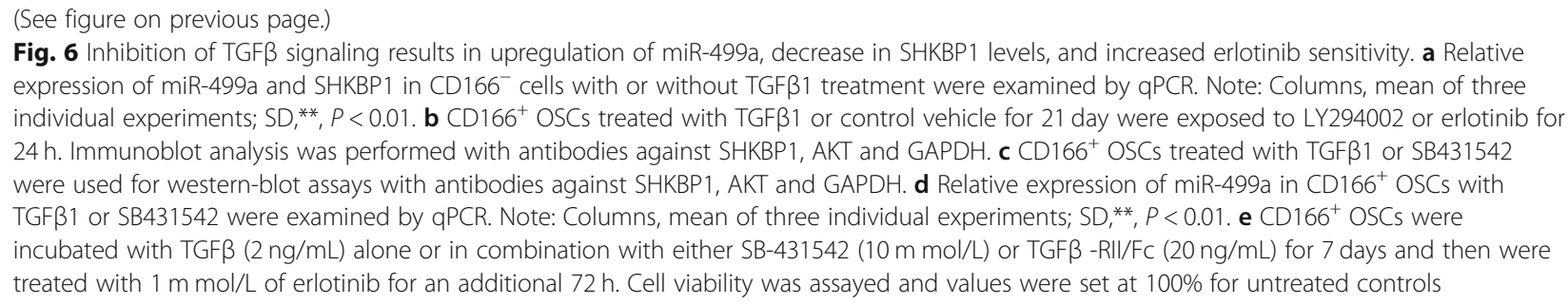

transfected with wild type SHKBP1 3'-UTR was significantly reduced in Lv-miR-499a group. On the contrary, the effect of Lv-miR-499a was completely abrogated in the mutant construct. Moreover, to investigate the correlation of miR-499a and SHKBP1 in OS patient cohort, we detected the expression of miR-499a and SHKBP1 in 10 paired $\mathrm{CD}_{166}{ }^{+} \mathrm{OSCs}$ and corresponding $\mathrm{CD} 166^{-}$ cells from OS tissues by qPCR. It was shown that miR-499a levels were declined in $\mathrm{CD}_{166}{ }^{+}$OSCs compared with those in $\mathrm{CD}_{166^{-}}$counterparts, while trend of SHKBP1 expression was contrary (Fig. 5c), which, obviously, indicated that SHKBP1 was negatively correlated with miR-499a level in OS tissues.

\section{TGF $\beta$-induced EMT results in decreased miR-499a, upregulation of SHKBP1, and increased erlotinib resistance}

To test the correlation between TGF $\beta$ and miR-499a, CD166 $6^{-}$cells were exposed to TGF $\beta 1$ in a time course. We found that SHKBP1 expression was elevated with TGF $\beta 1$ treatment (Fig. 6a). As the acquisition of an erlotinib-resistant EMT phenotype in response to TGF $\beta$ was associated with a significant increase in AKT activity, we, next, detected the role of AKT in SHKBP1 upregulation. $\mathrm{CD}_{166^{+}}$OSCs were treated with erlotinib or LY294002 (PI3K inhibitor). It showed that SHKBP1 expression was upregulated in $\mathrm{CD}_{166^{+}}$OSCs (Fig. 6b). Although both of erlotinib and LY294002 reduced basal expression of SHKBP1, only LY294002 resulted in a markedly inhibition of SHKBP1 in CD166 ${ }^{+}$OSCs treated with TGF $\beta 1$ for 20 days (Fig. 6b). These data suggest that basal EGFR activity induces an auto-regulatory expression of SHKBP1. We, then, blocked TGF $\beta$ signalling in CD166 ${ }^{+}$ OSCs with SB-431542, a potent inhibitor of the activin receptor-like kinase (ALK) receptors family. CD166 ${ }^{+}$ OSCs cultured with SB-431542 showed decreased level of p-AKT and SHKBP1 (Fig. 6c), while the expression of miR-499a was markedly enhanced (Fig. 6d). Moreover, both SB-431542 and TGF $\beta$ RII/Fc (recombinant TGF $\beta$ receptor II, which binds to and inhibits TGF $\beta 1$, TGF $\beta 3$, and TGF $\beta 5$ ) increased erlotinib sensitivity of $\mathrm{CD} 166^{+}$ OSCs (Fig. 6e). It suggests that TGF $\beta$-induced EMT results in the decreased miR-499a, enhanced SHKBP1 expression, and increased erlotinib resistance.
As EGFR-independent activation of the PI3K-AKT pathway has frequently been seen in cells that develop resistance and is thought to confer resistance to EGFR TKIs [22]. We further sought here to determine whether EMT-associated PI3K-AKT pathway was also involved in regulating the expression level of SHKBP1. Treatment of $\mathrm{CD}_{166}{ }^{+}$OSCs with either an AKT1/2 kinase inhibitor (AKI, at 5 and $10 \mathrm{mM}$ ), a MEK inhibitor (U0126, at 5 and $10 \mathrm{mM}$ ), or PI3K inhibitor (LY294002, at 5 and $10 \mathrm{mM}$ ) decreased SHKBP1 expression in association with the specific inhibition of each targeted pathway (Additional file 1: Figure S2A).

By further define the role of SHKBP1 in EGFR activity regulation, we demonstrated that SHKBP1 knockdown in $\mathrm{CD}_{166}{ }^{+}$OSCs resulted in an increase of EGFR phosphorylation in response to treatment with EGF (Additional file 1: Figure S2B). Furthermore, exposure to each inhibitor (LY294002, AKI, or U0126, at lower dose indicated above) increased the ratio of phospho-EGFR to EGFR upon ligand stimulation (Additional file 1: Figure S2C), consistent with the role of SHKBP1 in regulating EGFR activity. These data implies that TGF $\beta$-induced activation of AKT co-opts an increased SHKBP1 expression, which further regulates EGFR activity.

\section{Overexpression of miR-499a inhibits TGF $\beta$-induced resistance in vitro and in vivo}

To further confirm whether miR-499a overexpression can inhibit TGF $\beta$-induced erlotinib-resistance, a lentiviral-based approach was used to overexpress miR-499a: miR-499a mimics (Lv-miR-499a) or NC (Lv-NC). Also, SHKBP1 was knocked down by lentiviral-mediated si-SHKBP1 (si-SHKBP1). With increasing concentrations of erlotinib, the percentage of viable cells in si-SHKBP1-OSCs and Lv-miR-499a-OSCs decreased more rapidly than Lv-NC and si-NC (Fig. 7a). Furthermore, Lv-miR499a-OSCs showed reduced expression of EMT-related factors (Fig. 7b), however, the EMT-related factors were increased when Lv-miR-499a-OSCs were treated with TGF $\beta 1$ (Fig. 7b).

In vivo assays, we obtained 5 human OS tissues that were directly xenografted into nude mice. We injected $\mathrm{CD}_{166}{ }^{+}$OSCs clustered to the left and $\mathrm{CD}_{166}{ }^{-}$cells 

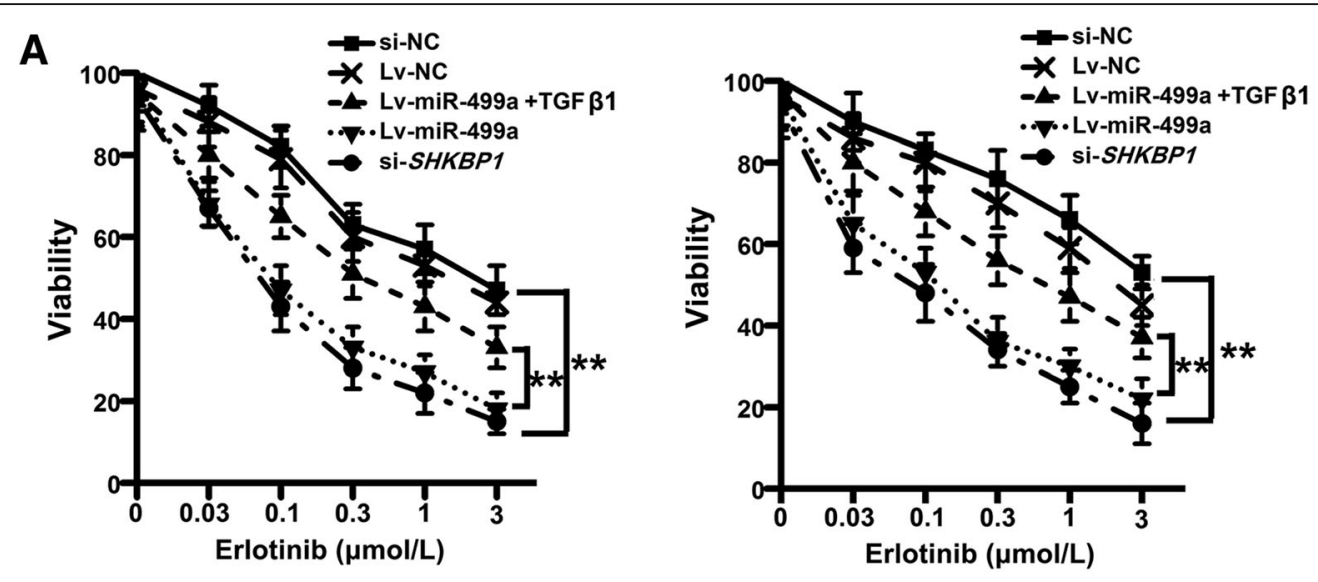

B
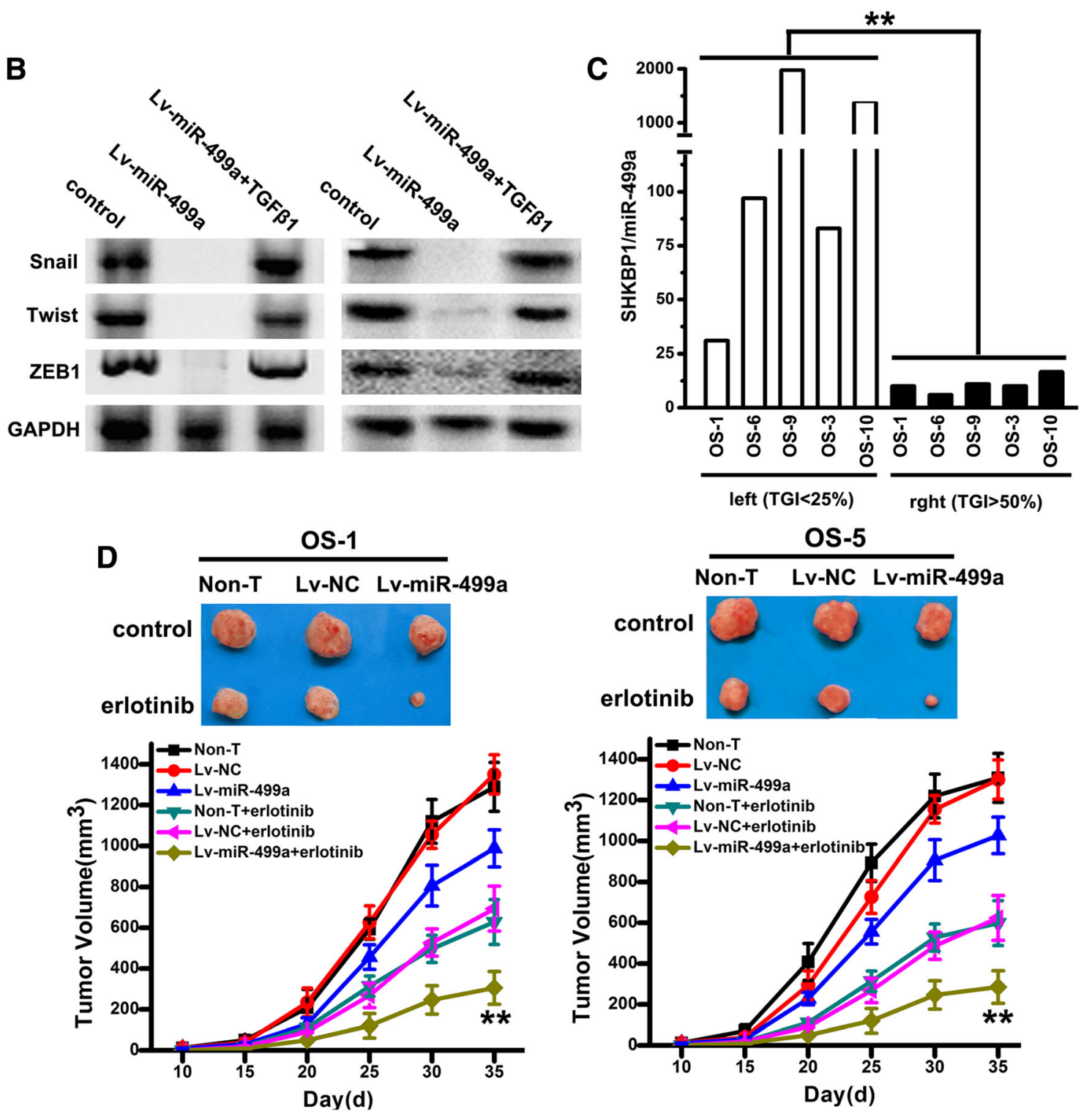

Fig. 7 (See legend on next page.) 
(See figure on previous page.)

Fig. 7 Overexpression of miR-499a inhibits TGF $\beta$-induced resistance in vitro and in vivo. a With increasing concentrations of erlotinib from 0.03 to $3 \mu \mathrm{mol} / \mathrm{L}$, the percentage of viable cells of CD166 ${ }^{+}$OSCs infected with LV-miR-499a, LV-NC, si-SHKBP1 or si-NC were measured by MTT. Note: Columns, mean of three individual experiments; $S D,{ }^{* *}, P<0.01$. b Western-blotting was used with antibodies specific for Snail, Twist, and ZEB1 in CD166 ${ }^{+}$OSCs with or without infection of Lv-miR-499a. GAPDH was used as the control. c RNA was extracted from 5 OS directly xenografted tumors Levels of miR-499a were measured by qPCR. Note: Columns, mean of three individual experiments; $\mathrm{SD}_{1}^{* *}, P<0.01$. d The potential of tumor initiation of CD166 ${ }^{+}$OSCs, Lv-NC-OSCs and si-SHKBP1- OSCs fractions by subcutaneous injection, and representative tumor volumes were measured following treatment with or without three cycles of erlotinib. Note: Columns, mean of three individual experiments; $S D_{1}^{* *}, P<0.01$

clustered on the right. Relative tumor growth inhibition (TGI, the relative tumor growth of treated mice divided by relative tumor growth of control mice) in response to erlotinib $(35 \mathrm{mg} / \mathrm{kg})$ was calculated. Xenografts that display a high SHKBP1/miR-499a ratio tended to cluster on the left side of the chart, indicating that they were more resistant to erlotinib (Fig. 7c), which is in line with the clinic cohort results in Fig. 5c. We, next, conducted a tumorigenesis study to evaluate the role of miR-499a in erlotinib resistance of $\mathrm{CD} 166^{+}$OSCs. We injected CD166 ${ }^{+}$OSCs (non-T) and CD166 ${ }^{+}$OSCs infected with lentivirus mediated miR-499a mimics (Lv-miR-499a) or NC (Lv-NC) to build xenograft model on NOD-SCID mice. We found that xenograft in Lv-miR-499a group were slightly smaller (Fig. 7d), although no significant difference was observed. Upon intratumor injection with erlotinib, the size of xenograft in Lv-miR-499a group were significantly reduced (following the three cycles of treatment) in comparison with those in $\mathrm{Lv}-\mathrm{NC}$ and CD166 ${ }^{+}$OSCs group (Fig. 7d).

\section{Discussion}

Cancer stem cell-like cells (CSCs) have been identified in an increasing number of malignancies. Nevertheless, little is known about what regulates their critical ability to therapeutic resistance. CD166 has hardly been used as the cell-surface marker for sorting OSCs, even though Brune JC, et, al. [23] found that OS-derived mesenchymal stromal cells (MSC) showed normal MSC morphology and expressed the typical MSC surface marker profile (CD105/CD73/CD90/CD44/HLA-lassI/CD166 positive. Here, we found that the presence of a variable fraction of $\mathrm{CD}_{166^{+}}$cell populations in 10 out of 10 primary OS samples. These $\mathrm{CD}_{166^{+}}$cell populations were demonstrated not only bearing enhanced self-renewable and tumorigenic ability, but also resistant to erlotinib.

Erlotinib, a receptor TKI, is a drug used to treat non-small cell lung cancer, pancreatic cancer and several other types of cancer. It has been shown to be effective in patients with or without EGFR mutations [24, 25]. Certain mutations in the EGFR TK domain is one of the factors lead to the resistance to certain TKIs [14]. However, on the other hand, more and more studies showed that the genetic alterations are present in only a minority of patients who partially respond to treatment and are rare in tumors other than NSCLC [15, 26, 27]. Thus, the sensitivity of only a few tumors to EGFR TKIs can be explained by the presence of EGFR TK domain mutations. Actually, there are many other primary resistance mechanisms, include amplification of the MET gene [28], EMT [29], and cancer stem cell-like cells [30], contributing to the resistance to EGFR TKIs. In order to be able to provide treatment selectively to those patients who do not harbor EGFR mutations but will nonetheless respond to EGFR TKIs, there is an urgent need to define the precise molecular mechanisms underlying resistance to EGFR TKIs, and to identify specific biomarkers capable of predicting therapeutic response.

In OS, in vitro studies have reported the expression of EGFR as well as effective inhibition of OS growth by EGFR inhibitors $[18,19]$. Here, we did not identify known mutations of TK domain from exons 18 to 21 that have been associated with constitutive EGFR activation in $\mathrm{CD}_{166^{+}}$ cells from these 10 primary OS tissue samples, which is in line with the results of the former publications [24, 25].

TGF $\beta$ s are believed to regulate tumor initiation and progression. According to the cancer type and tumor development timing, TGF $\beta$ s act as both tumor suppressors and tumor promoters: however, it is now well accepted that TGF $\beta$ s act as tumor promoters during the late stages of carcinogenesis to stimulate angiogenesis and immune evasion by inducing EMT. Previous studies have demonstrated that TGF $\beta$ plays a key role in promoting EMT driven by a network of transcriptional repressors that include SNAIL1, ZEB1, ZEB2, and TWIST [31]. In OS, studies demonstrated that TGF $\beta$ s expression were enhanced, and TGF $\beta$ s affected OS growth and lung metastatic development [9], suggesting that TGF $\beta$ plays a pro-tumoral effect in OS. Nevertheless, the downstream mechanism underlying TGF $\beta$-induced EMT in OS is unclear. In this study, we found that, in $\mathrm{CD}_{166^{+}}$OSCs, TGF $\beta$ expression level was increased. TGF $\beta$ induced $\mathrm{CD}^{-166^{-}}$cells to undergo an EMT-associated kinase switch that renders them resistant to EGFR TKIs, which suggests that increased autocrine exposure to TGF $\beta$ may be a driving force behind the erlotinib-resistant phenotype.

Accumulated studies uncovered that miR-499a was decreased in several cancers, including pancreatic cancer [32], hepatocellular carcinoma [33] and oral squamous cell carcinoma [34], functioning as the tumor suppressor. In OS, it 


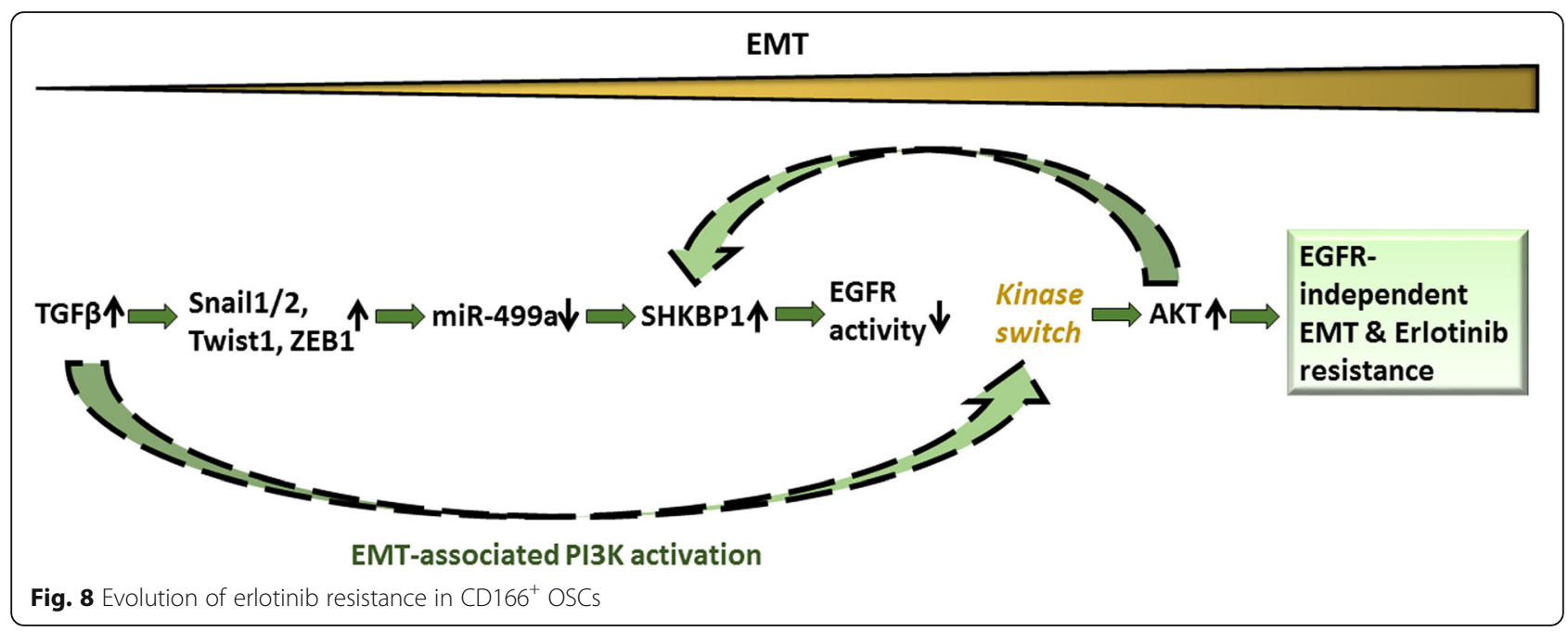

was found inhibiting OS cell proliferation [35], however, the biological function and underlying mechanisms of miR-499a in OSCs was unclear. In this study, by characterizing the down-stream mechanisms of TGF $\beta$-induced EMT in OS, we found that miR-499a was significantly reduced upon TGF $\beta$ treatment. Further mechanisms study defined that EMT factors, Snail1 and Zeb1, bound to the miR-499a promoters directly and regulated miR-499a at transcriptional level. As for its downstream signaling pathway, miR-499a was found targeting SHKBP1. Studies showed that compared with healthy individual's serum, SHKBP1 protein expression in the serum of patients with lymph node metastasis and liver metastasis was significantly elevated [36], but studies on the regulating mechanisms SHKBP1 is few. Here, we unveiled that TGF $\beta$-induced EMT in $\mathrm{CD}_{166}{ }^{+}$OSCs results in decreased miR-499a and enhaced SHKBP1 expression level. As EGFR-independent activation of the PI3K-AKT pathway has frequently been seen in cells that develop resistance and is thought to confer resistance to EGFR TKIs [22], we further sought here that EMT-associated PI3K-AKT pathway co-opts to regulate the basal expression level of SHKBP1 in CD166 ${ }^{+}$OSCs. As for the downstream of SHKBP1, our data indicated that SHKBP1 regulated EGFR activity to lead to further EGFR TKIs resistance. Recently, Lifeng Feng, et, al., [37] found that SHKBP1 affected EGFR signaling that required at least one intact PXXXPR motif, which gives the insight of the possible molecular mechanisms of SHKBP1 in EGFR activity regulation. Therefore, TGF $\beta$-mediated suppression of the miR499a unleashes expression of SHKBP1, which in turn quenches EGFR activity. The elevation of SHKBP1 following TGF $\beta$-induced EMT is sustained by EGFR-independent activation of AKT because this is reduced by PI3K inhibitors, but not by erlotinib.

In clinic, SHKBP1 expression level was found increased in OS samples compared with that in their adjacent normal counterparts. Meanwhile, SHKBP1 was negatively correlated with miR-499a level in CD166 OSCs and corresponding $\mathrm{CD}_{166^{-}}$cells. Further xenografts assays showed that a high SHKBP1/miR-499a ratio tended to increased resistance to erlotinib. These results indicate that an elevated SHKBP1/miR-499a ratio may have clinical value as a predictive biomarker to characterize the erlotinib-resistant OS.

\section{Conclusion}

In conclusion, our data demonstrate that the TGF $\beta$ miR-499a-SHKBP1 network orchestrates the EMT-associated kinase switch that induces resistance to EGFR TKIs in OSCs (Fig. 8). We also suggest that an elevated SHKBP1/ miR-499a ratio is a molecular signature that characterizes the erlotinib-resistant OS, which may have clinical value as a predictive biomarker. Our data further suggest that inhibition of the molecular determinants of the EMTassociated kinase switch, here is TGF $\beta$, may reverse the chemo-resistance of OSCs to EGFR inhibitors.

\section{Additional file}

Additional file 1: Table S1. Osteosarcoma patients' characteristics. Figure S1. miR-499a is directly regulated at transcriptional level by Snail1 and Zeb1. Figure S2. TGF $\beta$-induced activation of AKT co-opts SHKBP1 that further regulates EGFR activity in CD $166^{+}$OSCs. (DOCX $394 \mathrm{~kb}$ )

\section{Abbreviations}

ChIP: Chromatin immunoprecipitation; CSCs: Cancer stem cells; EGFR: Epidermal growth factor receptor; EMT: Epithelial-to-mesenchymal transition; FASC: Fluorescence-activated cell sorting; MSCs: Mesenchymal stromal cells; NSCLC: Non-small cell lung cancer; OS: Osteosarcoma; OSCs: Osteosarcoma stem cell-like cells; qPCR: quantitative real-time RT-PCR; TGFB: Transforming growth factor beta; TK: Tyrosine kinase; TKIs: Tyrosine kinase inhibitors 


\section{Acknowledgements}

This work is supported by Medical Peak Discipline Construction Project of Xuhui District (grant number: 15303) and Medical Science and Technology Project of Xuhui District (grant number: SHXH201709).

\section{Authors' contributions}

TW and DW: contribution to the conception or design of the work; the acquisition, analysis, or interpretation of data for the work; LZ, PY, JW, QL and FY: Drafting the work or revising it critically for important intellectual content; FL: Agreement to be accountable for all aspects of the work in ensuring that questions related to the accuracy or integrity of any part of the work are appropriately investigated and resolved. All authors read and approved the final manuscript.

\section{Funding}

This work is supported by the Shanghai Xuhui District Medical Peak Subject Project (SHXH201710) and the Xuhui District Medical Science and Technology Project (SHXH201709).

\section{Availability of data and materials}

The datasets used and/or analysed during the current study are available from the corresponding author on reasonable request. All data generated or analysed during this study are included in this published article and its Additional file 1 .

\section{Ethics approval and consent to participate}

All studies on mice were conducted in accordance with the National Institutes of Health 'Guide for the Care and Use of Laboratory Animals' and were approved by the ethical committee of the Eighth People's Hospital of Shanghai.

Informed consent for the additional core-needle biopsy and experimental use of tumor samples was obtained from all patients, following a protocol approved by the Ethics Committee of the Eighth People's Hospital of Shanghai.

\section{Consent for publication}

All authors consent for publication of this study.

\section{Competing interests}

The authors declare that they have no competing interests.

\section{Publisher's Note}

Springer Nature remains neutral with regard to jurisdictional claims in published maps and institutional affiliations.

\section{Received: 14 February 2019 Accepted: 25 April 2019} Published online: 28 May 2019

\section{References}

1. Isakoff MS, Bielack SS, Meltzer P, Gorlick R. Osteosarcoma: Current Treatment and a Collaborative Pathway to Success. J. Clin. Oncol. Off. J. Am. Soc. Clin. Oncol. 2015;33(27):3029-35 PubMed PMID: 26304877. Pubmed Central PMCID: 4979196

2. Meyers PA, Healey JH, Chou AJ, Wexler LH, Merola PR, Morris CD, et al. Addition of pamidronate to chemotherapy for the treatment of osteosarcoma. Cancer. 2011;117(8):1736-44 PubMed PMID: 21472721. Pubmed Central PMCID: 3059356

3. Collins M, Wilhelm M, Conyers R, Herschtal A, Whelan J, Bielack S, et al. Benefits and adverse events in younger versus older patients receiving neoadjuvant chemotherapy for osteosarcoma: findings from a metaanalysis. J. Clin. Oncol. Off. J. Am. Soc. Clin. Oncol. 2013;31(18):2303-12 PubMed PMID: 23669227.

4. Deshmukh A, Deshpande K, Arfuso F, Newsholme P, Dharmarajan A. Cancer stem cell metabolism: a potential target for cancer therapy. Mol cancer. 2016;15(1):69 PubMed PMID: 27825361. Pubmed Central PMCID: 5101698.

5. Hong IS, Lee HY, Nam JS. Cancer stem cells: the 'Achilles heel' of chemoresistant tumors. Recent Pat Anticancer Drug Disco. 2015;10(1):2-22 PubMed PMID: 25479037.

6. Zhang W, Zhao JM, Lin J, Hu CZ, Zhang WB, Yang WL, et al. Adaptive Fibrogenic Reprogramming of Osteosarcoma Stem Cells Promotes Metastatic Growth. Cell reports. 2018;24(5):1266-77 e5 PubMed PMID: 30067981.
7. Crasto JA, Fourman MS, Morales-Restrepo A, Mahjoub A, Mandell JB, Ramnath K, et al. Disulfiram reduces metastatic osteosarcoma tumor burden in an immunocompetent Balb/c or-thotopic mouse model. Oncotarget. 2018; 9(53):30163-72 PubMed PMID: 30046395. Pubmed Central PMCID: 6059028.

8. Zavell PM. Perinatal tips. Mich Med. 1971;70(25):924 PubMed PMID: 5098449.

9. Lamora A, Talbot J, Bougras G, Amiaud J, Leduc M, Chesneau J, et al. Overexpression of smad7 blocks primary tumor growth and lung metastasis development in osteosarcoma. Clin Cancer Res. 2014;20(19):5097-112 PubMed PMID: 25107916.

10. Kadam PD, Chuan HH. Erratum to: Rectocutaneous fistula with transmigration of the suture: a rare delayed complication of vault fixation with the sacrospinous ligament. Int Urogynecol J. 2016;27(3):505 PubMed PMID: 26811110.

11. Derynck R, Muthusamy BP, Saeteurn KY. Signaling pathway cooperation in TGF-beta-induced epithelial-mesenchymal transition. Curr. Opin. Cell Biol. 2014;31:56-66 PubMed PMID: 25240174. Pubmed Central PMCID: 4657734.

12. Penuelas S, Anido J, Prieto-Sanchez RM, Folch G, Barba I, Cuartas I, et al. TGF-beta increases glioma-initiating cell self-renewal through the induction of LIF in human glioblastoma. Cancer Cell. 2009;15(4):315-27 PubMed PMID: 19345330.

13. Ikushima H, Todo T, Ino Y, Takahashi M, Saito N, Miyazawa K, et al. Gliomainitiating cells retain their tumorigenicity through integration of the Sox axis and Oct4 protein. J. Biol. Chem. 2011;286(48):41434-41 PubMed PMID: 21987575. Pubmed Central PMCID: 3308855.

14. Thabit $H$, Tauschmann M, Allen JM, Leelarathna L, Hartnell S, Wilinska ME, et al. Home use of an artificial Beta cell in type 1 diabetes. N Engl J Med. 2015; 373(22):2129-40 PubMed PMID: 26379095. Pubmed Central PMCID: 4697362.

15. van den Bent MJ, Brandes AA, Rampling R, Kouwenhoven MC, Kros JM, Carpentier AF, et al. Randomized phase II trial of erlotinib versus temozolomide or carmustine in recurrent glioblastoma: EORTC brain tumor group study 26034. J Clin Oncol. 2009;27(8):1268-74 PubMed PMID: 19204207. Pubmed Central PMCID: 2667826.

16. Lee JA, Ko Y, Kim DH, Lim JS, Kong CB, Cho WH, et al. Epidermal growth factor receptor: is it a feasible target for the treatment of osteosarcoma. Cancer Res Treat. 2012:44(3):202-9 PubMed PMID: 23091447. Pubmed Central PMCID: 3467424.

17. Gleeson RP, Ayub M, Wright JT, Wood CB, Habib NA, Soutter WP, et al. Fatty acid control of growth of human cervical and endometrial cancer cells. Br J Cancer. 1990;61 (4):500-3 PubMed PMID: 2331435. Pubmed Central PMCID: 1971358.

18. Do SI, Jung WW, Kim HS, Park YK. The expression of epidermal growth factor receptor and its downstream signaling molecules in osteosarcoma. Int J Oncol. 2009;34(3):797-803 PubMed PMID: 19212684.

19. Freeman SS, Allen SW, Ganti R, Wu J, Ma J, Su X, et al. Copy number gains in EGFR and copy number losses in PTEN are common events in osteosarcoma tumors. Cancer. 2008;113(6):1453-61 PubMed PMID: 18704985. Pubmed Central PMCID: 3529469.

20. Barr S, Thomson S, Buck E, Russo S, Petti F, Sujka-Kwok I, et al. Bypassing cellular EGF receptor dependence through epithelial-to-mesenchymal-like transitions. Clin exp metastasis. 2008;25(6):685-93 PubMed PMID: 18236164. Pubmed Central PMCID: 2471394

21. Sevelda F, Mayr L, Kubista B, Lotsch D, van Schoonhoven S, Windhager R, et al. EGFR is not a major driver for osteosarcoma cell growth in vitro but contributes to starvation and chemotherapy resistance. J Exp Clin Cancer Res. 2015;34:134 PubMed PMID: 26526352. Pubmed Central PMCID: 4630894.

22. Engelman JA, Zejnullahu K, Mitsudomi T, Song Y, Hyland C, Park JO, et al. MET amplification leads to gefitinib resistance in lung cancer by activating ERBB3 signaling. Science. 2007;316(5827):1039-43 PubMed PMID: 17463250.

23. Brune JC, Tormin A, Johansson MC, Rissler P, Brosjo O, Lofvenberg R, et al. Mesenchymal stromal cells from primary osteosarcoma are non-malignant and strikingly similar to their bone marrow counterparts. Int I Cancer. 2011; 129(2):319-30 PubMed PMID: 20878957.

24. Kobayashi K, Hagiwara K. Epidermal growth factor receptor (EGFR) mutation and personalized therapy in advanced nonsmall cell lung cancer (NSCLC). Target Oncol. 2013;8(1):27-33 PubMed PMID: 23361373. Pubmed Central PMCID: 3591525.

25. Qi WX, Shen Z, Lin F, Sun YJ, Min DL, Tang LN, et al. Comparison of the efficacy and safety of EFGR tyrosine kinase inhibitor monotherapy with standard second-line chemotherapy in previously treated advanced nonsmall-cell lung cancer: a systematic review and meta-analysis. Asian Pac J Cancer Prev. 2012;13(10):5177-82 PubMed PMID: 23244131. 
26. Tsao MS, Sakurada A, Cutz JC, Zhu CQ, Kamel-Reid S, Squire J, et al. Erlotinib in lung cancer - molecular and clinical predictors of outcome. N Engl J Med. 2005;353(2):133-44 PubMed PMID: 16014883.

27. Mikkelsen MK, Thomsen FB, Berg KD, Jarden M, Larsen SB, Hansen RB, et al. Associations between statin use and progression in men with prostate cancer treated with primary androgen deprivation therapy. Scand J Urol. 2017;51(6):464-9 PubMed PMID: 28831860

28. Ito T, Kumagai Y, Itano K, Maruyama T, Tamura K, Kawasaki S, et al. Mathematical analysis of gefitinib resistance of lung adenocarcinoma caused by MET amplification. Biochem Biophys Res Commun. 2019;511(3): 544-50 PubMed PMID: 30824185

29. Izumchenko E, Chang X, Michailidi C, Kagohara L, Ravi R, Paz K, et al. The TGFbeta-miR200-MIG6 pathway orchestrates the EMT-associated kinase switch that induces resistance to EGFR inhibitors. Cancer Res. 2014;74(14): 3995-4005 PubMed PMID: 24830724. Pubmed Central PMCID: 4122100.

30. Fan Y, Xue W, Schachner M, Zhao W. Honokiol eliminates glioma/ glioblastoma stem cell-like cells via JAK-STAT3 signaling and inhibits tumor progression by targeting epidermal growth factor receptor. Cancers. 2018; 11(1). PubMed PMID: 30587839 . Pubmed Central PMCID: 6356849.

31. Roberts $A B$, Wakefield $L M$. The two faces of transforming growth factor beta in carcinogenesis. Proc Natl Acad Sci U S A. 2003;100(15):8621-3 PubMed PMID: 12861075. Pubmed Central PMCID: 166359.

32. Li F, Liang J, Bai L. MicroRNA-449a functions as a tumor suppressor in pancreatic cancer by the epigenetic regulation of ATDC expression. Biomed Pharmacother. 2018;103:782-9 PubMed PMID: 29684857.

33. Shan YF, Huang YH, Chen ZK, Huang KT, Zhou MT, Shi HQ, et al. miR499A>G rs3746444 and miR-146aG>C expression and hepatocellular carcinoma risk in the Chinese population. Genet Mol Res. 2013;12(4):5365-71 PubMed PMID: 24301908

34. Hou YY, Lee JH, Chen HC, Yang CM, Huang SJ, Liou HH, et al. The association between miR-499a polymorphism and oral squamous cell carcinoma progression. Oral Dis. 2015;21 (2):195-206 PubMed PMID: 24690080.

35. Liu J, Huang L, Su P, Song T, Zhang W, Fan J, et al. MicroRNA-499a-5p inhibits osteosarcoma cell proliferation and differentiation by targeting protein phosphatase 1D through protein kinase B/glycogen synthase kinase 3beta signaling. Oncol lett. 2018;15(4):4113-20 PubMed PMID: 29556286. Pubmed Central PMCID: 5844143

36. Darmanis S, Cui T, Drobin K, Li SC, Oberg K, Nilsson P, et al. Identification of candidate serum proteins for classifying well-differentiated small intestinal neuroendocrine tumors. PLoS One. 2013;8(11):e81712 PubMed PMID: 24282616. Pubmed Central PMCID: 3839889.

37. Feng L, Wang JT, Jin H, Qian K, Geng JG. SH3KBP1-binding protein 1 prevents epidermal growth factor receptor degradation by the interruption of c-Cbl-CIN85 complex. Cell Biochem Funct. 2011;29(7):589-96 PubMed PMID: 21830225. Pubmed Central PMCID: 4534006

Ready to submit your research? Choose BMC and benefit from:

- fast, convenient online submission

- thorough peer review by experienced researchers in your field

- rapid publication on acceptance

- support for research data, including large and complex data types

- gold Open Access which fosters wider collaboration and increased citations

- maximum visibility for your research: over $100 \mathrm{M}$ website views per year

At BMC, research is always in progress.

Learn more biomedcentral.com/submissions 